\title{
Una cohorte de artistas-gestores
}

\author{
A Cohort of Artists-Managers
}

\author{
Lucas Rimoldi y Alicia Monchietti \\ CONICET, Argentina \\ Ilrimoldi@yahoo.com
}

\begin{abstract}
Proponemos el análisis por cohorte (Mason y Wolfinger, 2001) de un grupo de escritores/ directores/actores argentinos que comienzan a estrenar en la escena alternativa hacia 2001. El concepto de cohorte permite visualizar características comunes en individuos que entran a un sistema al mismo tiempo y su utilización aspira a superar algunas limitaciones del uso más común pero menos definido, en teoría literaria, teatral y de la cultura, del concepto de generación. Destacamos un uso específico de la gestión por parte de estos artistas como rasgo caracterizador, que facilita su proyección internacional y asemeja su perfil al de jóvenes emprendedores pertenecientes a otros contextos, como México o Inglaterra.
\end{abstract}

Palabras clave: Cohorte, gestión, teatro argentino.

We propose a cohort analysis (Mason and Wolfinger, 2001) of a group of argentine writers/directors/actors who start working in the alternative scene by 2001 . The concept of cohort can help to visualize common characteristics in individuals entering a system at the same time and its use aims to overcome some limitations of the more common but less defined use in literary, dramatic and cultural theory of the concept of generation. We highlight a specific use of management by these artists as a main feature, which facilitates their international projection and resembles the profile of young entrepreneurs belonging to other contexts, such as Mexico or England.

Keywords: Cohort, Management, Argentine theatre. 
Con el fin de analizar el efecto cohorte en un grupo de teatristas argentinos, inicialmente recordemos que cuando se observa el cambio o evolución temporal de creencias y actitudes dentro de una sociedad, pueden diferenciarse distintos tipos de influencias. Unas se deben a sucesos que alcanzan al conjunto de la población; otras están asociadas al período en que se encuentra cada persona y sus procesos de crecimiento, maduración, envejecimiento; y puede observarse un tercer nivel que surge de la combinación de los anteriores: la edad en la que cada individuo ha atravesado los distintos períodos del acontecer social, coincidente para todos aquellos sujetos que han nacido en un mismo lapso. Según Mason y Wolfinger, una cohorte es un grupo de individuos entrando a un sistema al mismo tiempo, por lo que se supone experimentan acontecimientos específicos que los afectan de manera simultánea. De este modo, "los individuos en una cohorte se presume tienen similitudes debido a las experiencias compartidas que los diferencian de otras cohortes" (Mason y Wolfinger, 2001: 2189; nuestra traducción):

A cohort can be a set of people, automobiles, trees, whales, buildings; the possibilities are endless. System entry can refer to birth -a person is born, or to any dated event- a machine is assembled on a particular date. A set of individuals who begin serving a prison term at the same point in time might also define a cohort for certain purposes, in which case "birth" refers to initiation into a particular role system and "age" becomes duration (time since system entry). The breadth of the time interval that defines membership in a particular cohort depends on analytic considerations and the nature of the phenomenon under study (2189).

Como señalan los autores, las consideraciones analíticas y la naturaleza del fenómeno estudiado inciden en la amplitud del intervalo que define la pertenencia a una cohorte, observación relevante para el propósito de nuestro estudio. La noción de cohorte, utilizada en demografía, sociología y medicina, permite ver y describir determinadas características comunes de los sujetos que la integran, y en este caso, establecer con mayor precisión algunas variables estéticas. Reduce la ambigüedad frente al uso más antiguo y extendido, pero menos unívoco y peor definido, en teoría literaria, teatral y de la cultura, del concepto de generación, como en "generación del 37", "generación del 98" o "generación X".

En relación con la literatura acerca del tema, no hemos encontrado estudios por cohortes en el campo del arte hispanoamericano, aunque sí un intento embrionario de adopción de este enfoque para literaturas en lengua inglesa (Blom, 2002). No obstante y dada la coincidencia de época, de edades de los artistas estudiados, y por su particular uso del método generacional, dentro de la crítica argentina podemos referirnos a un trabajo de Drucaroff relativa a nueva narrativa argentina o "NNA" (2011). Drucaroff busca definir un conjunto de narradores jóvenes para, desde una lectura social, relevar ciertas tematizaciones o manchas temáticas (2011: 21) recurrentes en sus ficciones. Varias son las diferencias respecto de nuestros objetivos y enfoque: la autora renuncia abiertamente a la nitidez en los límites del recorte, 
pues si bien apela al método generacional, lo hace en sentido laxo, en tanto, según ella, por tratarse de objetos culturales una mayor precisión no resulta conducente. Al justificar la elección de esta herramienta generacional cita el trabajo del chileno Ricardo Cuadros respecto de la historia y limitaciones de este método (2011: 30). Simultáneamente convoca al crítico brasilero Idelber Avelar y su categoría de literatura de postdictadura ligada a las literaturas argentina, chilena y brasilera (2011: 27). Más adelante ensaya un deslinde y sistematización de (al menos) dos generaciones de postdictadura para la "NNA", con escritores nacidos hasta 1970 y posteriores (2011: 169-181). Y establece siete hitos históricos desde 1973 hasta 2001 para hacerlos jugar con la edad de los prosistas y, obviamente, con su producción. Este caso nos sirve entonces para fundamentar nuestra crítica a este tipo de enfoque, con algunos interrogantes que aquí cobran la siguiente formulación: el término postdictadura ¿es el más apropiado para subsumir esa multiplicidad de aconteceres históricos, los que, por otro lado, anteceden y suceden al gobierno militar? Sin negar su impacto social e histórico, ¿hasta qué punto la dictadura militar es el hecho más significativo para un escritor nacido con posterioridad a 1983, cuya producción artística queda así ligada a ese rótulo? Longitudinalmente, ¿hasta cuándo se extiende o extenderá esta idea de postdictadura? ¿Y cuántas generaciones internas se detectan dentro del intervalo elegido y bajo qué criterios? Más allá de la laxitud del enfoque en lo demográfico, también es posible preguntarse si los a priori ideológicos pensados en torno de la noción de generación no condicionan en exceso su caracterización así como la lectura de los textos, orientándolas enfáticamente a una interpretación contenidista ( $v . g r$. manchas temáticas).

En este estudio nos proponemos caracterizar con mayor precisión el subcampo de producción teatral que nuestra cohorte reclama para sí. Dentro de su perfil se integran unos 25 artistas cuya franja etaria oscila actualmente entre los 35 y 45 años, partícipes de la transformación explosiva del sistema teatral argentino que se remonta a fines de los 90: José María Muscari, Laura López Moyano, Matías Feldman, Santiago Gobernori, Javier Drolas, Agustín Mendilaharzu, Luciano Cáceres, Carolina Tejeda, Walter Jakob, Alberto Ajaka, Lola Arias, Mariana Chaud, Marcelo Mininno, Patricio Abadi, Ariel Farace, William Prociuk, Mariano Pensotti, Maximiliano de la Puente, Claudio Tolcachir, Julieta de Simone, Mariela Asensio, Carla Crespo, Germán Rodríguez, Laura Paredes, Moro Anghileri, Pilar Gamboa. ${ }^{1}$ Detectamos como identificatorios los siguientes rasgos: el ingreso al campo del teatro con los primeros estrenos importantes hacia 2000; la capacitación y desempeño en los roles de escritura dramática, dirección y actuación en proyectos escénicos alternativos; la habilidad de gestión; la capacidad de desarrollar diferentes estrategias asociativas de producción.

\footnotetext{
1 Por razones metodológicas, limitamos este estudio a lo que sucede en la metrópolis. Entre los recursos utilizados para la recolección de datos se contó con la entrevista individual semidirigida y focalizada, de diseño flexible y de carácter eminentemente cualitativo, habiéndose apuntado a que los sujetos definieran su práctica artística. Los datos emergentes han sido contrastados con los generados durante la investigación mediante la observación participante. Tanto para el procesamiento como para la lectura de los mismos se ha recurrido al análisis de contenido.
} 
Creemos oportuno recordar que desde muy distintas disciplinas se coincide hoy en que el universo del hombre es un universo simbólico (homo symbolicus). Diversos autores han señalado cómo los símbolos artísticos y míticos se determinan en relación con las estructuras histórico-políticas y psicosociales de los grupos humanos; la creación simbólica integra un vasto sistema de equilibrio con fuerza de cohesión. Desde nuestro marco teórico, entendemos la subjetividad de estos artistas en tanto consecuencia, en parte, de la trama que la cultura produce, quedando impregnada por los discursos epocales que la instituyen. La impronta de época abarca creencias y valores vigentes en el campo artístico. Todos estos artistas han experimentado como hecho demográfico fundamental el haber atravesado la peor quiebra financiera de Argentina, que eclosionó en 2001 como colofón del proceso neoliberal de privatizaciones. Esa crisis y la variante actual de neoliberalismo (McRobbie, 2008) son estímulos recibidos por la cohorte como tal. Según señalan varios autores, hoy cohortes como la estudiada se hayan bajo la influencia de tendencias globales del mercado del trabajo cultural (McRobbie, 2008; Canclini, 2012).

El teatro experimental intenta profundizar la búsqueda de originalidad expresiva propia de todo arte. Los exponentes más inspirados exhiben o impulsan las nuevas formas de la expresión de los cambios culturales o sociopolíticos, y una parte de la crítica especializada logra identificarlas, y luego explicarlas y clasificarlas. Consideramos que al definirse, estos artistas se autodesignan dentro de una zona de autonomía y vanguardia entendida como subcampo de producción pura, que al enunciar su diferencia se polariza respecto del teatro comercial y del oficial, entendido como lo "viejo o superado". La intencionalidad explícita de (re)inventar procedimientos mediante la investigación formal y conceptual, de huir de un teatro didáctico y artísticamente ingenuo, es la directriz de su práctica. Estos elementos también son observables en otras etapas de nuestra historia teatral y en otros campos teatrales: por ejemplo, en ese "arte de inventar" procedimientos ya inventado en los 90 (Bourdieu, 1995: 376). Pero hemos determinado otros rasgos que permiten establecer con mayor precisión las coordenadas de su posición, como la capacidad de gestión. Así y desde el punto de vista diacrónico, es con esta cohorte que se observa con mayor nitidez el viraje de un artista que pasa a ser no solo un creador-intelectual, sino también un artista-gestor.

Mason y Wolfinger indican que el análisis por cohorte es más interesante cuando hay información retrospectiva disponible (2001: 2191). También es cierto que, metodológicamente, el análisis cualitativo de cohortes se enriquece cuando es posible tener en cuenta el contexto, y la biografía. Por eso para comprender esta figura novedosa es pertinente retrotraernos a algunos antecedentes cercanos dentro de la historia del teatro independiente argentino. En los años 80 , su vertiente más under supo experimentar nuevas modalidades de escritura teatral, y la hiperinflación que estalló al final de la década potenció el trabajo mediante una dinámica autogestiva. Durante los 90 se canonizaron poéticas más intelectuales, y grupos como El Periférico de Objetos o De la Guarda conquistaron la escena internacional mientras la globalización tocaba al micromundo teatral porteño, abriendo el acceso de los artistas a importantes festivales. 
Heredera de esta tradición, la cohorte que nos ocupa asume la gestión teatral de una manera propia. La opinión más difundida tanto entre críticos como artistas es que las prácticas escénicas que provocaron la expansión del off hacia 2000 fueron producto de la autogestión entendida como capacidad de los artistas de crear con pocos recursos materiales, de manera autofinanciada y por fuera de los apoyos estatales o institucionales. Sin embargo, aunque es notorio que nuestros artistas saben y pueden trabajar con recursos escasos, eso no significa que trabajen o hayan trabajado con nada. Esto debe matizarse para evitar una imagen naif e idealizada de sus procesos creativos. Afinando el sentido que le otorgamos a la expresión artista-gestor, tampoco referimos a la figura del gestor cultural como se la comprende en el ámbito europeo o norteamericano, no se trata de un profesional dedicado a organizar actividades culturales con el fin de nutrir con ellas un medio; ni de un artista volcado a esta profesión o que la ejerza de manera paralela.

Estamos hablando de un artista que desarrolla la gestión de manera activa, con el fin de obtener recursos que le permitan llevar adelante su propia actividad, sus proyectos, sus espectáculos, desde su visión de lo que es el teatro (Pérez Martín, 2002: 65). Vemos entonces la gestión como parte de una modalidad teatral con dispositivos propios, surgida y afianzada dentro de un medio que, aún signado por la crisis económica, se mantuvo rico en diferentes recursos que estimularon la efervescencia y la posibilidad de existencia de una "primavera escénica". La consideración de las condiciones sociales, políticas y económicas contextuales, nos permite interpretar además la capacidad de gestión de nuestros artistas como una estrategia de afrontamiento ante situaciones conflictivas, como las vividas en los momentos socialmente más problemáticos, entre 2000 y 2004.

Esta nueva categoría de artista-gestor tiene que ver directamente con la manera en que estos sujetos se apropian y utilizan las informaciones y los saberes sobre el trabajo artístico. La capacidad de gestión implica negociar espacios, auspicios de instituciones estatales o entes privados, obtener legitimidad artística y asumir determinadas políticas culturales. Los sujetos de esta cohorte son networkers, habilidosos en la búsqueda, obtención y explotación sistemática de subsidios, becas e invitaciones a festivales y giras. ${ }^{2}$ Invierten en lograr un reconocimiento ligado al acceso a fondos, premios y giras. Son asimismo hábiles para establecer vínculos con instituciones extranjeras, el éxito alcanzado en las etapas de distribución por los festivales europeos se ha constituido en una marca distintiva y de pertenencia, por lo que se vuelve una meta para artistas que aspiran a ingresar al campo: discípulos y competidores. Otra de estas señas es la obtención del Premio S. ${ }^{3}$ Estas marcas y recursos se unen a una ideología y unas creencias que

2 Instituto Nacional del Teatro, Proteatro y Fondo Nacional de las Artes son las entidades que administran recursos públicos destinados a las artes escénicas en Argentina. Acerca de la historia y regulación de estos organismos consúltese Bayardo, 2008: 33-38. Al de estos organismos, puede sumarse el apoyo proveniente de instituciones extranjeras, embajadas, fundaciones $y$, en menor medida, mecenas privados.

3 La captura de valor que se deriva del proceso de internacionalización tiene una faceta simbólica y otra más mundana. El premio $S$ es un estímulo que se otorga anualmente desde 
los diferencian y que ellos, estratégicamente, necesitan mantener vigentes para sostener esa diferencia que define su posición (Bourdieu). La frontera entre los iniciados y los legos -como también entre vanguardistas y rezagados o artistas comerciales- conlleva necesariamente un grado de cierre grupal, y otorga ciertos beneficios simbólicos en juego y que se potencian por el efecto de cuerpo.

Una de las características más notables y señaladas de los sujetos es su capacidad y necesidad de agruparse. ${ }^{4}$ Esta cohorte es un ecosistema de creatividad y sociabilidad. Según Sloterdijk, un espacio que sus integrantes han abierto "porque ellos le han dado forma, contenido, extensión y duración relativa al habitarlo[s]" (Sloterdijk, 2011: 52). El concepto de esfera de Sloterdijk como lugar atmosférico-simbólico, explica la climatización simbólica del espacio común en tanto producción originaria de cualquier grupo. Así, en este caso la cohorte funciona como incubadora de experimentación en el trabajo autónomo creativo, proveyendo al mercado laboral de la cultura urbana de jóvenes con competencias múltiples. A su vez Buenos Aires como una gran capital creativa les facilita el acceso a las instituciones de la cultura que brindan recursos como contrataciones y subsidios. La existencia de fondos destinados a las artes escénicas conlleva todo un aparato burocrático y administrativo que atañe a su regulación, lo que hace también de la gestión una necesidad impuesta por el medio. En este ida y vuelta se instaura y retroalimenta una red de obligaciones y alianzas, de competencias y tensiones. A tal punto esta compleja dinámica se ha instalado, que ha tornado esta habilidad necesaria, incluso surgieron personas que, por un honorario, ofrecen realizar las tareas de gestión en el lugar de los artistas o aspirantes a artistas. Entonces si como hemos postulado la gestión es desde una perspectiva una estrategia de afrontamiento, reparemos ahora en que lo es no solo ante situaciones sociales conflictivas sino respecto de las generadas en el campo artístico, y probablemente un intento de adaptación al medio. En cuanto al matiz asociativo, Artei y Escena son dos colectivos de artistas que facilitan la gestión de ayudas a las salas independientes; este ejemplo nos muestra a los autores interesados en discutir las políticas culturales. ${ }^{5}$

Podemos aludir a esta franja de jóvenes creativos como trendsetters, techsetters, hipsters, o emprendedores (Canclini, 2012: 14), aparentemente los más competentes para fabricar y comunicar el arte en la sociedad del conocimiento, sociedad que Han considera signada por el giro digital y donde el exceso de información es difícilmente manejable (Han, 2014). Ellos

hace más de diez años a dos jóvenes teatristas (pueden ser dramaturgos, directores o actores). Las primeras en recibirlo fueron Mariana Chaud y Laura Paredes; Walter Jakob y Agustín Mendilaharzu lo obtuvieron hace cinco años. El monto adjudicado -en ese entonces, 10.000 pesos argentinos- debe ser utilizado para la creación de un nuevo espectáculo. Además el mecenas tiene un espacio que ofrece como sala de ensayo a todos los que alguna vez obtuvieron el premio.

4 Según Woodyard, dentro de Latinoamérica la situación teatral de Argentina pone de manifiesto una mentalidad grupal que no se da tanto en otros países. Comunicación personal, Lawrence, University of Kansas, 2009.

5 Varios integrantes de la cohorte poseen, dirigen o administran sus salas, por ejemplo Santiago Gobernori y Matías Feldman (Defensores de Bravard), Patricio Abadi (Onírico), Alberto Ajaka (Escalada), Claudio Tolcachir (Timbre 4). 
producen, gestionan y organizan de manera flexible y multitask (Canclini, 2012: 75). Los emprendimientos de los millenialls se encuentran enhebrados por las amistades y la afinidad social. Coincidiendo con nuestra descripción, Canclini afirma que "en la actualidad estos procesos de gestión adquieren nuevas modalidades", así como matices que no pueden ser comprendidos desde los modelos convencionales; implican gestionar la propia imagen respondiendo a convocatorias específicas sin más estímulo que la propia iniciativa (62-63). Las competencias intelectuales necesarias para los nuevos modelos de gestión se corresponden, en otro aspecto, con el giro hacia el discurso, la teoría y la teorización, el que produce cierta disputa de los artistas con la crítica en el despliegue de los discursos que interpretan la obra y su proceso. Por ejemplo, las Conferencias performáticas organizadas por Lola Arias consistieron en una selección de artistas reflexionando en público acerca de sus estrategias laborales, con hincapié en aquellas asociadas a la viabilización de algunos de sus proyectos. A propósito de estas Conferencias, donde actores, cineastas y performers utilizaron sus computadoras personales y diversos archivos multimedia, confirmamos el uso de la mediación tecnológica por los artistas de esta cohorte, quienes en ocasiones emplean soportes tecnológicos como herramientas creativas. Algunas de sus obras tienen elementos interactivos y son concebidas para un espectador que introduce un componente de aleatoriedad.

Según Moscovici (1986), las representaciones sociales existen en la cultura y en la mente de las personas, modelizando valores de época y orientando activamente actitudes y comportamientos. El desarrollo de la gestión escénica es un contenido consensuado que se ha ido consolidando como un elemento del núcleo figurativo del campo representacional compartido por un sector relevante de la dramaturgia argentina. Los integrantes de esta cohorte comparten así un campo representacional que moldea una concepción específica de lo que es el teatro. Esa concepción y la práctica comunes elaboradas a lo largo del tiempo ayudan a establecer los límites de un espacio reclamado por oposición al del teatro oficial y al del comercial. A pesar de ello, estos artistas tienen un tránsito asiduo por el primer ámbito, y más eventual por el último. El ciclo Biodramas muestra tanto tales incursiones como los lazos asociativos que permitieron una convocatoria recíproca en las obras de ese proyecto. 6

En tanto ocasionalmente trabajan en el teatro comercial, el off es no solo un ámbito de autonomía estética y de experimentación, sino un semillero que nutre medios más heterónomos (Bourdieu, 1995: 323), en un flujo que llega hasta las industrias del cine y la televisión. El film de Mariano Llinás Historias extraordinarias, de más de cuatro horas de duración, rodado con un monto mínimo y de excelentes resultados artísticos (ensambla con un ritmo narrativo envidiable tres historias paralelas y otros tantos episodios intercalados), constituye una muestra privilegiada de cómo el vitalismo teatral de esta cohorte impregna al ámbito del cine (Pérez, 2012: 4-7). Demuestra la

6 Conforman el circuito oficial Complejo Teatral de Buenos Aires, Centro Cultural Ricardo Rojas, Centro Cultural Recoleta, Secretaría de Cultura del Gobierno de Buenos Aires. De Biodramas participó la mayoría de los artistas de esta cohorte. 
fascinación que ejerce el teatro alternativo así como similitudes en la gestión y producción de este tipo de teatro y de cine.

Todas estas cuestiones aparecen retratadas o literalmente llevadas a escena en la obra Por el dinero, del ciclo Proyectomanual. ${ }^{7}$ Usina de la experimentación teatral desde la reapertura democrática, el Centro Cultural Ricardo Rojas cruza o superpone en su propuesta teatral esos dos circuitos con estéticas y modos de producción deferentes: por un lado el oficial con un flujo de dinero público y una mirada institucional que atañe a la selección, producción y programación de las obras; por otro, el off y su ideología estética donde confluyen la asunción de riesgos creativos y el rechazo de lo convencional. Con sus tres espacios teatrales (la más tradicional Batato Barea y las salas Cancha y Biblioteca), el CCRRojas prioriza la experimentación entendida como oportunidad de estreno para creadores nóveles, y brinda una suma de dinero acotada para montar las producciones. Las obras suelen pensarse, integrarse y ofrecerse en ciclos, donde unos tres espectáculos realizan una función semanal a lo largo de tres meses. Su audiencia es por lo general joven y vinculada al ámbito artístico. También en su programa pueden tener participación artistas de trayectoria, como es el caso que nos ocupa. Los espectáculos del CCRRojas más exitosos posteriormente pueden ser programados en alguna sala alternativa.

Así sucedió con algunas obras de ProyectoManual, con ediciones en 2011, 2012 y 2013. Los artistas, especialmente convocados, elijen un manual de instrucciones, el que deben integrar en una dramaturgia. La inclusión de materiales no estéticos y la investigación teatral a partir de variables no dramáticas emparentan este proyecto con los ciclos Biodramas y Proyecto Museos (y de manera más tangencial con Conferencias performáticas y Confesionario): en el primer caso el artista crea una dramaturgia a partir de la vida de un argentino vivo; en el segundo (una experiencia de los años 90) se exploró el espacio de diferentes museos de la ciudad, particularmente ajenos a la esfera del arte, y como resultado se mostró un espectáculo.

Por el dinero es una creación de Luciana Acuña, Alejo Moguillansky y Mathieu Perpoint, quienes tomaron el Manual de danzas nativas como referencia para crear una obra deconstructiva y metateatral. En esta experiencia de escritura conjunta los roles de autor, director, actor, bailarín, músico, deliberadamente no son fijos, se comparten y se alternan. Con ella los autores enfocan algunos de los aspectos más privados de la vida del artista, como el vínculo entre vocación y sustentabilidad, y la relación dinero/clase social/gestión artística. En el ambiente íntimo de la sala Biblioteca abre el espectáculo una proyección en video de una entrevista que realizaron al economista Paul Segal y su mujer Ingrid Bleynat, donde el primero explica qué es el PBI, brinda el índice para Argentina y vincula el concepto de clase media a ese indicador. Asimismo, señala que la clase media se determina no tanto por los ingresos, sino por los gastos o tipos de consumos. Se proyecta

7 Producido y curado por el Centro Cultural Ricardo Rojas. La expresión "curador" proviene del ámbito de la plástica y pretende subrayar la ordenación, análisis y legitimación que forman parte de los procesos de selección a cargo de una persona idónea en el desempeño de tal función. 
un gráfico de la historia de ingresos de los artistas actualizando los índices inflacionarios de los últimos diez años. Luego los tres intérpretes realizan un contrapunto en el que comparan partida por partida sus gastos mensuales. Proyectan imágenes "recauchutadas" de otro proyecto artístico, en un supuesto acto estético revolucionario justificado con cierta ironía cuando mencionan el presupuesto acotado de 10.000 pesos que obtuvieron para producir el espectáculo. Como otros momentos de la obra, se trata de una autorreferencia a su proceso de gestión y producción. Luego de una coreografía, Acuña lee un recorte de su biografía, pero en segunda persona y señalando con gestos a los otros intérpretes durante el relato. Mediante ese recurso narrativo se da cuenta de los lazos de intimidad que los vinculan en la vida real, se destaca la intercambiabilidad de los roles como sello de su manera de entender el arte, pero sobre todo se marca un desplazamiento que debe advertirnos de que más allá de la impronta autobiográfica, se está exponiendo un recorte y una ficción:

Te mudás a Buenos Aires con una beca de estudio que te paga $\$ 500$ por mes. [...] Año 2001. Tu mamá está preocupada por vos, pero vos ni siquiera entendés por qué. Tu vida es simple y feliz. No gastás dinero en las cosas que gastás ahora. [...] Ese mismo año con tu grupo estrenan su segunda obra, una pegada. Las entradas se agotan en cada función, hacen entre 3 o 4 giras por año, sacan unos 1.500 dólares cada uno. Esta es la única obra que les dio plata en su vida. [...] te vas a Europa con otra beca de estudios. Vivís con lo justo e invertís todo el dinero en unos workshops carísimos en la campiña francesa, que pagás 600 euros cada uno. Un amigo te dice por teléfono que con dos de esos workshops acá te comprás un auto. [...] Te enamorás de ese director de cine, que resultó ser yo, y yo me enamoro de vos. Entonces decidimos unir nuestras economías, e irnos a vivir juntos, aunque [...] entre los dos no sumamos el dinero para un alquiler. Al año siguiente, te invitan a festivales, residencias, conferencias o funciones en teatros europeos y yanquis. Como cobrás en dólares, ese año tenés el mayor promedio de ingresos de toda tu vida. Ganás más de 1.000 dólares por mes, pero la racha te dura nada más que 4 meses. [...] Hoy, 2013, tu grupo supuestamente es reconocido, pero la verdad es que vos no ves un peso, salvo por alguna gira en las mismas dos putas universidades en Estados Unidos que los invitan siempre. Tu economía se basa en los 2.000 pesos de clases del IUNA y en las coreografías que hacés para obras de otros. [...] Ahora, cuando mirás la proyección de los próximos meses ves que, como en toda tu vida, no hay nada asegurado. Te hacés preguntas nuevas, sobre el dinero que ganás, sobre los gastos que tenés, sobre cuáles son tus necesidades básicas... ¿Entonces al final vos formás parte de una burguesía, "baja", "media", "alta", qué importa.. ? ¿Y yo soy el padre de esa familia, que dice ser un cineasta de vanguardia pero que gana el dinero con propagandas de Fiat, de Clarín Olé, de gaseosas, o lo que mierda haya que vender? [...] El verano pasado, en tu casa en San Francisco, encontramos un manual de danzas nativas. Lo abrís y te preguntás cómo sería tu vida si te hubieses dedicado al folklore (Por el dinero, s/p, mimeo, gentileza de los autores).

El relato biográfico apunta a mostrar el despertar vocacional, la trayectoria profesional, y los avatares de las gestiones del artista independiente, que busca equilibrar sus metas estéticas y sus necesidades económicas. Sigue 
una coreografía con música folklórica que refuerza el procedimiento del desplazamiento, en tanto los movimientos de baile son clásicos; más adelante en la coreografía del tema "Pala Pala Pulpero" los que se desplazan son los géneros. A su momento, la biografía de Mathieu Perpoint es contada desde el punto de vista de la bailarina pero en este caso la narra el tercer actor, mientras Perpoint intercala reiteradamente el estribillo " $Q$ ' el horror I 'argent". El momento más significativo en relación con la gestión llega cuando Acuña y Perpoint leen veintidós e-mails intercambiados por Moguillansky con varios productores, gestores culturales y artistas europeos, entre mayo de 2012 y enero de 2013. Lo que comenzó como una promesa de apoyo económico de 7.000 euros por parte del Instituto de Cine Sueco para una película de Moguillansky, se transmuta en la propuesta de que este obtenga 1.000 euros por filmar un corto para el proyecto Little Sun, una lámpara a energía solar para el tercer mundo diseñada por un artista islandés. Moguillansky filma sin su little sun, que nunca llega a Argentina, opta por viajar invitado a la presentación del proyecto en la Tate Modern de Londres, para terminar reclamando seis meses después los 2.600 euros de viáticos. En el medio, retenciones de materiales en la aduana, resoluciones "a la argentina", complicaciones del sistema bancario local y dilaciones y evasivas de los europeos. Los e-mails se leen acompañados de cómplices miradas a la audiencia, y el cambio de tono y de tempo, más la gestualidad facial, generan un efecto humorístico e irónico elegido para exponer los avatares de la gestión. Ese humor es la clave que otorga la distancia necesaria para mostrar zonas poco conocidas o expuestas, o hasta tabú, del mundo del arte.

La obra exhibe estos temas pero no debe tomarse como un testimonio directo. Simultáneamente, se adentra en aspectos de una concepción del teatro, la danza y el cine independientes indagando en los orígenes y variaciones de las representaciones comunes que los artistas tienen de ella; y por añadidura se deja leer como una narración de la manera en que tales representaciones se sostienen en una red vincular con el tiempo. Por el dinero enfoca deliberadamente esa concepción compartida que abarca estéticas, estrategias e ideologías, con la gestión como punta de lanza y tema fundamental del espectáculo. Y también muestra un sentido del término dramaturgia sostenido por esta cohorte: como concreción del deseo de trabajar y crear conjuntamente, generando en el encuentro de los artistas obras que se ajusten a sus inquietudes y realidades.

Más allá de este ejemplo, el análisis de su representación respecto del teatro nos permite interpretar una forma particular de agrupamiento en esta cohorte. Deducimos de las entrevistas que realizamos que sus integrantes parecen guiados por la búsqueda de reconocerse con sus pares, amigos y colaboradores, impelidos por la necesidad personal de hacer su propia experiencia, explorarla y disfrutarla al crear. En esta tendencia vincular inciden tanto su procedencia y trayectoria social como su estilo de vida y competencias enciclopédicas. Naturalmente, la base posibilitadora son las afinidades estéticas que confluyen en su sentido de lo artístico. Asimismo podemos observar aquí que esta cohorte no es producto de un recorte artificial sino que simultáneamente es un grupo natural. Y que la frontera que asegura su grado de cierre genera un efecto de endogamia artística y social: la cohorte encarna relaciones de poder y marca tendencia siendo modelo para grupos 
menos consagrados. ${ }^{8}$ Vinculado a la idea anterior es pertinente recordar que, según Bourdieu, en un subcampo de la creación teatral no consagrado a la obtención de éxitos masivos, los artistas no apuntan a satisfacer las demandas del "gran público", son conocidos y reconocidos por sus pares y solo por ellos. Lo que constituye una estrategia que produce su posicionamiento específico, más notoria en los inicios en la actividad (Bourdieu, 1995: 323, y también 222). ${ }^{9}$

Las características tipificadoras de esta cohorte no excluyen las diferencias individuales que aportan a la renovación -dentro de su seno y luego hacia zonas externas- de tendencias de escritura teatral y modelos de artista. Tales diferencias, según el Grupo de Berlín (Baltes et al., 2006), constituirían factores no normativos idiosincrásicos dentro de un sistema de influencias de cambio que afectan a grupos e individuos, y dentro del que, como venimos viendo, inciden efectivamente factores normativos relativos a la edad y factores normativos relativos a la historia o cohorte. Ejemplo de esas diferencias individuales es el retorno al realismo que autores como Jakob, Mendilaharzu, Tejeda o Chaud concretan en varias de sus obras, en un medio donde prima el rechazo a dicha estética. Jakob, hacedor de un teatro narrativo y de puro diálogo, prioriza el carácter literario de la dramaturgia y apuesta por una estética "convencional", aportando e introduciendo en el intercambio su sello personal. La tensión posible entre el bagaje acumulado y compartido y las diferencias individuales puede explicarse apelando al concepto de curso de vida, según este, cada sujeto no se comporta pasivamente en relación con las creencias sostenidas por determinado grupo, sino que de alguna manera modela y transforma lo que recibe. La formación en cine de este artista y lo que ella le significa respecto de su práctica teatral se traduce así en influencias de cambio debidas a factores idiosincrásicos. Por este tipo de dinamismos las representaciones que comparte una cohorte con el tiempo pueden encarnar en nuevas formas de crear, y de ser.

La posición de esta cohorte tiene que ver con su búsqueda de capital simbólico y no de capital económico, con la obtención de capital específico de

\footnotetext{
8 Según el Diccionario de la Real Academia Española la endogamia consiste en una actitud social de rechazo a la incorporación de miembros ajenos al propio grupo o institución. 9 "... uno tiene la sensación de que hay una gran disgregación, que se generan como 'islas' en las cuales hay una circulación restringida (a veces son tres los espectadores que están mirando una obra). [...] Somos como pequeños grupos huérfanos que hacemos nuestra propia producción y estamos en contacto con unos pocos. [...] En todo caso, sé que uno tiene acceso a un público muy minoritario. El público que accede a mi obra tiene que ver con el ambiente artístico o intelectual: gente que está en la universidad o que hace teatro, es una elite muy pequeña -ínfima, con relación a lo que es el público-. Creo que ese público reducido está abierto a un lugar de experimentación, está receptivo para lo que se le proponga. Nosotros hicimos cerca de un año de funciones y sentíamos que podíamos traspasar ese pequeño cerco del grupo de pertenencia y llegar a otra zona de gente que, tal vez, no está tan vinculada con la actividad teatral, y sin embargo entendieron y entraron al mundo que le propusimos". Declaraciones de Lola Arias en respuesta a una encuesta coordinada por Patricia Fischer, en Pellettieri, Osvaldo (2004, dir.), Teatro argentino y crisis 2001-2003. Buenos Aires, Eudeba, pp. 204-206. Para un ejemplo más actual véase nuestra entrevista a Walter Jakob, RIMOLDI, Lucas (2013). "Escritura en colaboración y revitalización del realismo. Entrevista con Walter Jakob", Latin American Theatre Review 47.1, pp. 145-154 (esp. 149-150).
} 
consagración y de beneficios de distinción y discriminación social (Bourdieu, 1995: 370, 384). Los que tienen más capital pueden tomar decisiones más libres y arriesgadas y se dirigen por lo tanto a donde hay menos competencia, menos saturación. Las diferencias en términos de capital se traducen en diferencias o desfases temporales, haciendo que los más enterados abandonen las posiciones en declive o amenazadas mientras que los que tienen mal sentido se dirigen a ellas (Bourdieu, 1995: 379, 387, 389). Esto nos permite entender, por un lado, el cuño experimentalista que la cohorte enarbola frente a un campo más amplio, pero también y dentro de ella, la restauración del realismo recién mencionada, por parte de algunos de sus integrantes.

Hacer existir una posición novedosa por delante de las ya establecidas es crear una vanguardia. Y mientras el tiempo transcurre, y como en el caso de otras vanguardias, esta cohorte se ha venido desarrollando gracias a las estrategias que paso a paso hacen sus productos más aceptables y consonantes con las visiones de mundo que a su vez van imponiéndose sucesivamente. Lo que se produjo no está hecho de una vez y para siempre, será hecho y rehecho cada vez que alguien se interese por la obra, la disfrute, la estudie, la clasifique: el discurso especializado sobre la obra es un momento de su producción, de la atribución de su sentido y valor. El público también participa de este proceso, en este caso recordemos que el valor de las entradas de los espectáculos ayudó en un inicio a consolidar, y luego retener, una audiencia que en determinado momento no podía acceder con tanta facilidad a obras más comerciales; se fortaleció allí un lazo, un gusto, un hábito y una fidelidad. Se trata de una sinergia que abarca un público dispuesto a adherir, recrear y crear junto a estos dramaturgos sueños, recuerdos, imaginarios, vidas. Involucra mayormente una clase media que desea y procura sostener un aire de libertad y de expresión amenazado en tiempos de crisis, frente a obras que precisamente suelen mostrar estas temáticas.

Mientras que esta cohorte ingresó al campo artístico en el pico de la crisis local de la privatización neoliberal -hecho significativo que incidió en su desarrollo y características-, sus saberes y modalidades se adaptan y actualizan hoy en el contexto de tendencias globales, por lo que su escenario es local y global. Según McRobbie, este tipo de escenarios aparentemente novedosos disimulan sin embargo una vuelta a modelos antiguos, elitistas y socialmente excluyentes, porque implican una precarización de las relaciones entre las instituciones y sus fuerzas de trabajo, de las que se autonomizan (McRobbie, 2008). Sería un modelo que normaliza la precariedad y la inseguridad, que bajo la apariencia de una supuesta modernización, tiende a marginalizar. La proliferación de puestos no remunerados, contratos basura o becas con cláusulas casi absurdas y desalentadoras (como vimos al analizar Por el dinero) nos habla eminentemente de una retribución simbólica pero no económica, que a veces no es suficiente. Institución y artistas se atraen y repelen a la vez, en un juego en el que a veces los creadores con menos capital económico "van por lana y salen trasquilados". Desde las consideraciones precedentes hablar de un sistema del arte posneoliberal carece de fundamento.

En conclusión, el concepto de cohorte ha resultado operativo al enfocar una etapa específica del teatro independiente argentino, permitiéndonos describir 
y ahondar en la comprensión de una de sus concepciones, protagónica, de la práctica escénica. En esta confluyen el desarrollo de la gestión con proyección internacional y la implementación de modalidades asociativas, como escritura en colaboración y rotación de roles. Estos artistas ocupan dentro del campo una zona competitiva y económicamente poco remunerativa, y esas modalidades comprenden una estrategia solidaria orientada a la permanencia y continuidad. Buscan la posibilidad de mantener una trayectoria que los avale y les permita aspirar a nuevas oportunidades de creación, y la gestión responde a esas necesidades laborales tanto como ha ido integrándose a una ideología estética. Nuestro análisis tuvo en cuenta, de manera multidimensional, factores interactuantes y sus procesos de cambio. En este sentido y advirtiendo que esta cohorte no se mantiene inmutable a lo largo de todo el intervalo considerado, observamos que si la gestión ha sido inicialmente una estrategia de afrontamiento ante una crisis, luego se integró a un metier, para hoy aparecer como un rasgo de la identidad del artista globalizado (y por tanto, como señala Canclini, común a artistas de otros países).

\section{Obras citadas}

Baltes, Paul, Lindenberger, Ulman y Staudinger, Ursula (2006). "Life Span Theory in Developmental Psychology". W. Damon y R. M. Lerner (Eds.). Handbook of Child Psychology: Vol. 1. Theoretical Models of Human Development, pp. 569-664.

Bayardo, Rubens (2008). "Políticas culturales en la Argentina". Canelas, Antonio y Bayardo, Rubens (Orgs.). Políticas culturales en Iberoamérica. Salvador: Edufba. pp. 19-49.

Blom, Mattias (2002). "The conceptualization and construction of a cohortbased inquiry into the US literary field". Poetics, 30. pp. 311-325.

Bourdieu, Pierre (1995). Las reglas del arte. Barcelona, Anagrama. (1998). La distinción. Criterio y bases sociales del gusto. Madrid: Taurus.

Drucaroff, Elsa (2011). Los prisioneros de la torre. Buenos Aires: Emecé.

García Canclini, Nestor (Coord., 2012). Cultura y desarrollo. Una visión crítica desde los jóvenes. Buenos Aires: Paidós.

Han, Byung-Chul (2014). En el enjambre. Barcelona: Herder.

Mason, William y Wolfinger, Nicholas (2001). "Cohort Analysis". Smelser, Neil y Baltes, Paul (Eds.). International Encyclopedia of the Social and Behavioral Sciences. Amsterdam: Elsevier Science. pp. 2189-2194. Disponible en http://papers.ccpr.ucla.edu/papers/PWP-CCPR-2001-005/ PWP-CCPR-2001-005.pdf

Mc Robbie, Ángela (2008). "The 'Losangelization' of London". Disponible en www.eipcp.net

Moscovici, Serge (1986). Pensamiento y vida social. Psicología social y problemas sociales. Barcelona: Paidós.

Pérez, Martín (2012). "Uno para todos todos para uno. Qué se puede hacer salvo hacer películas". Radar: 16, 833, pp. 4-7.

Pérez Martín, Miguel Ángel (2002). Gestión de proyectos escénicos. Ciudad Real: Ñaque.

Sloterdijk, Peter (2011). Esferas I. Madrid: Siruela. 